\title{
Effects of Locus Coeruleus Stimulation on Neuronal Activities in the Rat Superior Colliculus*
}

\author{
Yukihiko KaYAma and Hiromichi Sato \\ Department of Neurophysiology, Institute of Higher Nervous Activity, \\ Osaka University Medical School, Kita-ku, Osaka, 530 Japan
}

Summary In urethane-anesthetized rats, effects of locus coeruleus stimulation on spontaneous and photically evoked discharges of superior collicular neurons were studied. In any layer of the superior colliculus the inhibited neurons were more numerous than the facilitated ones, and the latter increased relative to the former from the superficial to the deep layer.

Key Words: locus coeruleus, superior colliculus.

The investigation of the neuronal activities in the cerebellum (HOFFER et al., 1973) and hippocampus (SEGAL and BLOOM, 1974) has revealed that the noradrenergic projection system of the locus coeruleus (LC) exerts an inhibitory action on target neurons. Recently it was found, however, that the noradrenergic control from the LC differed in nature according to species of neurons receiving it; in the dorsal lateral geniculate nucleus, relay neurons were excited while interneurons were inhibited when noradrenaline was applied iontophoretically or electrical stimulation was given to the LC (Rogawski and AgHAJANian, 1980a, b; KAYAMA et al., 1982).

Neurons in the superior colliculus (SC) can be classified into several groups according to their locations in the SC and functions (FukUdA et al., 1978b). The present study was therefore made to examine how LC stimulation differentially affects activities of the classified neurons of the SC.

LC stimulation was successfully examined in $98 \mathrm{SC}$ neurons in urethaneanesthetized rats (8-12 weeks old), some of which were immobilized by gallamine and ventilated artificially. Details of the method for positioning a stimulating electrode in the LC and the criteria for classifying SC neurons are described elsewhere (FuKuda et al., 1978b; Kayama, et al., 1982). To drive SC neurons photically, a light spot was turned on and off at the center of receptive fields

Received for publication May 31,1982

* This paper is dedicated to Dr. Kitsuya Iwama on the occasion of his retirement from Osaka University Medical School.

香山雪彦, 佐藤宏道 
plotted on a tangent screen (FUKUDA et al., 1979). The LC was stimulated with trained square pulses of $0.05 \mathrm{msec}$ duration from several seconds to several tens of seconds. They were $2-5 \mathrm{~V}$ at $200 \mathrm{~Hz}$ or $8-15 \mathrm{~V}$ at $20 \mathrm{~Hz}$.

Single shock stimulation of the optic chiasm elicited in the $\mathrm{SC}$ a field response whose shape was specific to the depths of the recording site, and unit activities could be recorded simultaneously with the field response (FUKUDA et al., 1978a, b). Thus, with the shape of the response it was easy to judge from what layers neurons were recorded. In this way the neurons recorded in the SC were divided into the following 3 groups; 1) neurons in the upper visual layer (stratum zonale and upper half of st. griseum superficiale; zone of horizontal cells (LANGER and LUND, 1974)), 2) neurons in the lower visual layer (lower half of st. griseum superficiale and st. opticum; zone of vertical cells (LANGER and LUND, 1974)), and 3) neurons in the deep, non-visual layer (st. griseum intermediale, album intermediale et griseum profundum).

With only a few exceptions, spontaneous discharges of SC neurons were either facilitated or inhibited by LC stimulation. The change of spontaneous discharges occurred with a latency of several seconds to several tens of seconds and became gradually manifest while the stimulation was continued. In Fig. 1, $\mathrm{A}, \mathrm{B}$, and $\mathrm{D}$ are sample records for the LC-induced inhibition, being distinguished from each other by the rapidity of the decrease of the discharge frequency. Record C, a typical example for the facilitation of spontaneous discharges, was obtained from the same electrode track as for record D with the same parameters of LC stimulation. It is suggested that excitation of the same group of LC neurons caused facilitation in one group of SC neurons and inhibition in the other. Whether LC stimulation caused facilitation or inhibition of spontaneous discharges, changes in the discharge frequency outlasted the stimulation by varying times not shorter than $10 \mathrm{sec}$.

In neurons recorded from the visual layer, effects of LC stimulation were tested upon photically evoked responses as well. The effects were either facilitatory or inhibitory on both of on- and off-responses. Records E and F of Fig. 1 are sample records for inhibition and facilitation of the photically evoked response, respectively. In E, while LC was stimulated, the photically evoked responses were reduced in the peak discharge frequency and made less sustained. In $F$, the photically evoked responses were affected by LC stimulation in a way virtually opposite to that in $\mathrm{E}$.

When the visual layer units were exhibiting the spontaneous discharges, the latter were usually affected by LC stimulation in qualitatively the same way as the photically evoked discharge. In some neurons the spontaneous discharges were inhibited more rapidly and severely than the photically evoked responses, so that the response became more conspicuous against the suppressed background. This may be the phenomenon described as "signal-to-noise ratio improvement" by MoISES et al. (1981). As for neurons exhibiting facilitation of the photically 

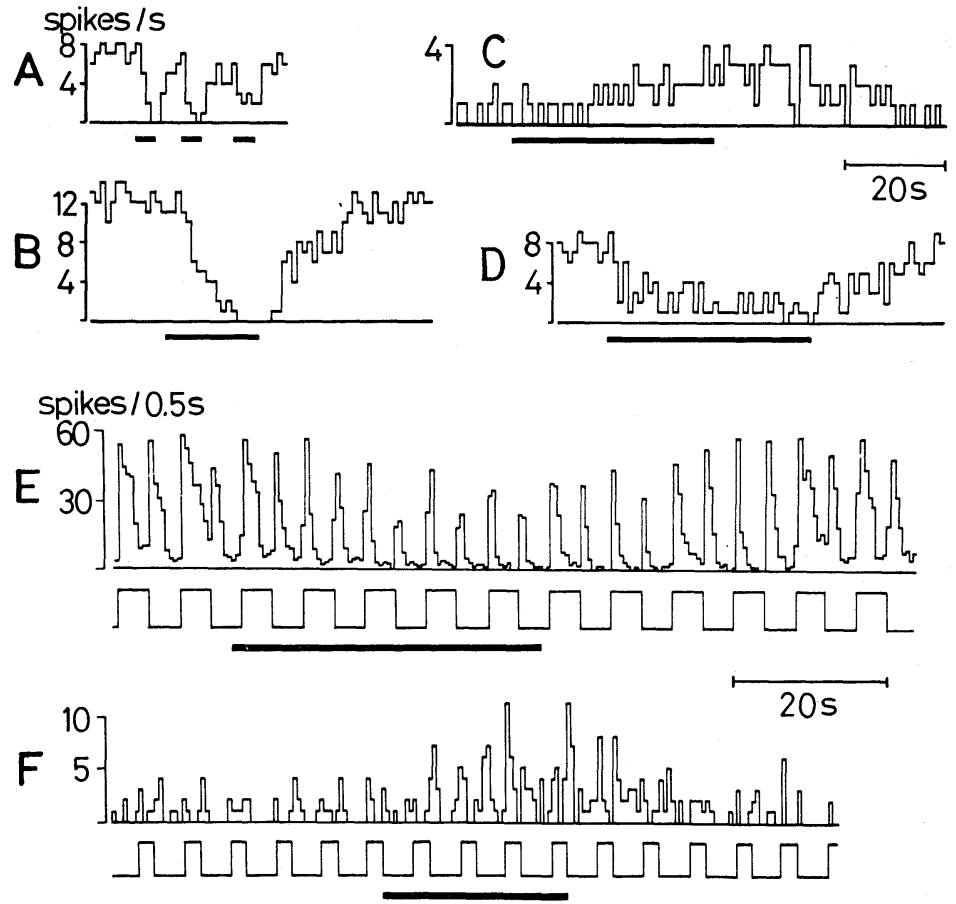

Fig. 1. Effects of LC stimulation on spontaneous discharges of 4 neurons (A, B, C, and D) and on visual responses of 2 neurons (E and F). Integrated discharge rate per sec (A to $D$ ) or per $0.5 \mathrm{sec}(\mathrm{E}$ and $\mathrm{F})$ is shown in the ordinate. Stimulation periods are shown by thick horizontal bars under each record. For neurons A, LC stimulation was tested 3 times; in the third trial the stimulus intensity was reduced to $2 / 3$ of the intensity in the first and second ones. Neuron A was recorded in the upper visual layer, neurons B, C, E, and F in the lower visual layer, and neuron D in the non-visual layer. Neurons $\mathrm{C}$ and $\mathrm{D}$ were recorded in the same electrode track and tested with LC stimulation of the same parameters. In $\mathrm{E}$ and $\mathrm{F}$, responses were evoked by turning a light spot on and off at the center of a receptive field (upswings of trains of square waves indicate light-on periods).

evoked responses due to LC stimulation, no good examples could be obtained for the signal-to-noise ratio improvement.

By testing the effects of LC stimulation upon the spontaneous discharges in many SC neurons of various layers, it was found that the ratio of the incidence of neurons exhibiting facilitation to those showing inhibition differed according to the layers in which the neurons were located. As shown in Table 1-I, the ratio of the facilitated neurons to the inhibited ones increases as one passes through the SC from superficial to deep. The same tendency can be found with regard to the effects on the photically evoked responses (Table 1-II).

The present experiment has shown that the noradrenergic control from the LC is either facilitatory or inhibitory on SC neurons. Although attempts were 
Table 1. The number of neurons affected by LC stimulation.

\begin{tabular}{lrrrr}
\hline \multicolumn{1}{c}{ Layer } & Inhibited & Facilitated & No effect & Total \\
\hline I. Spontaneous discharges & & & & \\
Upper visual & $9(90 \%)$ & $1(10 \%)$ & 0 & 10 \\
Lower visual & $25(64 \%)$ & $7(18 \%)$ & $7(18 \%)$ & 39 \\
$\quad$ Non-visual & $14(58 \%)$ & $8(33 \%)$ & $2(8 \%)$ & 24 \\
II. Visual responses & & & $1(25 \%)$ & 4 \\
Upper visual & $3(75 \%)$ & 0 & $6(24 \%)$ & 25 \\
Lower visual & $15(60 \%)$ & $4(16 \%)$ & \\
\hline
\end{tabular}

made to reveal the relation between the neuronal species and the nature of noradrenergic control exerted upon them, such remained unsuccessful. Instead, it was established that although in any layer of SC the inhibitory effect was more frequently observed than the facilitatory one, the ratio of the facilitated neurons to the inhibited ones increased from the upper to the lower visual layer and further to the deep, non-visual layer. The physiological meaning of such surface-todepth gradient of the probability of SC neurons for receiving facilitation or inhibition from the LC remains to be clarified in future experiments.

The authors are very grateful to Prof. Kitsuya Iwama for his kind advice and comments.

\section{REFERENCES}

Fukuda, Y., Sugitani, M., Sumitomo, I., and Iwama, K. (1979) Receptive field properties of cells in the dorsal part of the albino rat's lateral geniculate nucleus. Jpn. J. Physiol., 29: 283-307.

Fukuda, Y., Suzuki, D. A., and Iwama, K. (1978a) Characteristics of optic nerve innervation in the rat superior colliculus as revealed by field potential analysis. Jpn. J. Physiol., 28: 347-365.

Fukuda, Y., Suzuki, D. A., and Iwama, K. (1978b) A four group classification of the rat superior collicular cells responding to optic nerve stimulation. Jpn. J. Physiol., 28: 367384.

Hoffer, B. J., Siggins, G. R., Oliver, A. P., and Bloom, F. E. (1973) Activation of the pathway from locus coeruleus to rat cerebellar Purkinje neurons: Pharmacological evidence of noradrenergic central inhibition. J. Pharmacol. Exp. Ther., 184: 553-569.

Kayama, Y., Negi, T., Sugitani, M., and Iwama, K. (1982) Effects of locus coeruleus stimulation on neuronal activities of dorsal lateral geniculate nucleus and perigeniculate reticular nucleus of the rat. Neuroscience, 7: 655-666.

LANGer, T. P. and Lund, R. D. (1974) The upper layers of the superior colliculus of the rat: A Golgi study. J. Comp. Neurol., 158: 405-436.

Moises, H. C., Waterhouse, B. D., and Woodward, D. J. (1981) Locus coeruleus stimulation potentiates Purkinje cell responses to afferent input: The climbing fiber system. Brain Res., 222: 43-64.

Rogawski, M. A. and Aghajanian, G. K. (1980a) Activation of lateral geniculate neurons by norepinephrine: Mediation by an alpha-adrenergic receptor. Brain Res., 182: 345-359.

Rogawski, M. A. and Aghajanian, G. K. (1980b) Modulation of lateral geniculate neurone excitability by norepinephrine microiontophoresis or locus coeruleus stimulation. Nature, 287: 731-734.

Segal, M. and Bloom, F. E. (1974) The action of norepinephrine in the rat hippocampus. II. Activation of the input pathway. Brain Res., 72: 99-114. 